\title{
Zefferino Vitor de Meireles: impressão e civilidade na Corte do Rio de Janeiro (1808-1822)
}

Zefferino Vitor de Meireles: Printing and Civility in the Court of Rio de Janeiro (1808-1822)

\section{Myriam Paula Barbosa Pires \\ Mestre em História pela \\ Universidade do Estado do Rio de Janeiro (UERJ - Rio de janeiro / Brasil) e professora substituta no Departamento de História e no Colégio de Aplicação da mesma Universidade e-mail:my.paula@gmail.com}

\begin{abstract}
Resumo
0 artigo analisa a importância do oficio de impressor a partir da trajetória de vida do tipógrafo português Zefferino Vitor de Meireles e sua presença na Corte entre os anos de 1808 e 1825. Além de ter sido agente importante na consolidação de distintos trabalhos no interior da Tipografia da Impressão Régia, chegando até sua administração, Meireles fundou o periódico Diário do Rio de Janeiro tendo sido posteriormente dono de tipografia homônima. Fundada no bojo de crescimento da Modernidade nos trópicos, a referida tipografia foi parte integrante enquanto objeto e sujeito da nova cultura liberal que crescia. Noções de civilidade na época perpassam este trabalho.
\end{abstract}

\begin{abstract}
This article analyzes the importance of the printer trade focusing the trajectory of the Portuguese typographer Zefferino Vitor de Meireles and his presence in the Portuguese Royal Court between the years of 1808 and 1822. Besides being an important agent in the consolidation of remarkable works at the Tipografia da Impressão Régia, reaching to its administration, Meireles created the periodical publication Diário do Rio de Janeiro. Subsequently, he was also the owner of a homonymous typography. Established in the context of growth of the Modernity in the tropics, the quoted typography was an important member - as both object and subject - of the new increasing liberal culture. Aspects such as the notion of civility in that period are discussed in this work.
\end{abstract}

\section{Palavras-chave}

imprensa, modernidade, opinião pública

\section{Keywords}

press, modernity, public opinion 
0 periódico Diário do Rio de Janeiro circulou na Corte entre os anos de 1821 e 1878 . Em seu primeiro ano, saiu impresso diariamente, inclusive aos domingos. Optamos por atualizar a grafia dos termos de época a fim de proporcionar uma melhor compreensão do texto.

2

Os periódicos com perfil informativo eram a Gazeta do Rio de Janeiro (1808-1822) e o Volantim (setembro a outubro de 1822).

3

AZEVEDO, Manuel Duarte Moreira de. Origem e desenvolvimento da imprensa no Rio de Janeiro. Revista do Instituto Histórico, Geográfico e Etnográfico Brasileiro, Rio de Janeiro, T. XXVIII, p.106, 4º trimestre de 1865.

4

Diário do Rio de Janeiro (DRJ), n.11, 13 de agosto de 1822.

0 episódio foi narrado seguidamente na historiografia da imprensa. Todavia, sem indicações de documentação. 0 fato pode ser notado pela verificação da saída de Meireles da redação e do aviso de seu falecimento nas datas correspondentes ao que sinalizou a historiografia.

Segundo apontou Barbosa Lima Sobrinho, em primeiro de setembro de 1821, a Junta Diretora da Imprensa Régia publicava uma declaração ordenando que não se fizessem nas oficinas manuscritos ou impressos sem indicação de autoria e reconhecimento por tabelião público. Em caso de desobediência, o acusado poderia ser levado a julgamento, naquilo que 0 autor chamou de "condenação do anonimato", ver: SOBRINHO, Barbosa Lima. O problema da imprensa. Rio de Janeiro: Álvaro Pinto, 1923. p.166-168.

Cf. MOREL, Marco. Cipriano Barata na Sentinela da Liberdade. Salvador: Academia de Letras da Bahia / Assembléia Legislativa do Estado da Bahia, 2001. Uma relação de periódicos da Corte pode ser encontrada no "Catálogo de Jornais e Revistas do Rio de Janeiro existentes na Biblioteca Nacional (1808-1889)". Anais da Biblioteca Nacional. Vol.85. Rio de Janeiro: Fundação Biblioteca Nacional, 1881. p.1-208. Edição fac-similar.
Na manhã do dia 12 de novembro de 1822, algo mudava na rotina de muitos dos moradores desta cidade. 0 Diário do Rio de Janeiro, um conhecido periódico, não saiu'. Muitas poderiam ser as razões capazes de causar o impedimento da publicação de uma "folha" periódica na época. No caso de um importante jornal e efetivamente diário na Corte, entretanto, somente um episódio bastante significativo resultaria nessa condição. Naquele tempo tal ausência poderia provocar ainda certo burburinho, especialmente entre comerciantes e caixeiros, principais anunciantes e que possivelmente acostumaram-se, senão a ler, a saber das notícias diariamente. A esta altura, o Rio de Janeiro já contava com alguns poucos periódicos para anunciar produtos, informar a dinâmica dos portos e das marés, o horário das missas, o jogo de loteria, as festas e espetáculos ${ }^{2} \ldots$ Informações essenciais no cotidiano de uma cidade que se modernizava. Mais ainda, e como era o caso, se esta última se constituisse como sede de uma monarquia em que o movimento de entrada e saída de mercadorias (entre elas, os escravos) apresentava-se como a base de sustento de uma sociedade com novos hábitos e consumo.

Circulando nos diversos pontos da cidade, entre seus vários distritos, as páginas daquele importante impresso já faziam parte do cenário, informando e orientando negociantes de diversos ramos. Segundo anunciado pelo próprio veículo, o motivo da falta teria sido a morte do seu primeiro proprietário, redator e editor: Zefferino Vitor de Meireles. Consta que Zefferino foi morto por um desconhecido que após ter lido (ou sabido) de um aviso-denúncia publicado no Diário em 19 de agosto do mesmo ano teria resolvido a questão por seus próprios meios ${ }^{3}$. Eis o aviso:

0 sujeito que encerrou sua filha, no dia 23 de julho findo, em uma prisão incomunicável, dentro de sua casa, mantendo-a desde então com castigos que nem a lei, nem a humanidade podem tolerar queira soltar a dita senhora já e já, quando não, seu nome há de ser publicado, com uma relação fiel das circunstâncias (...) ${ }^{4}$.

Além de uma denúncia, o aviso tomou forma de ameaça em que o possivel pai poderia ser alvo de uma investigação policial. Se foi o redator ou não o responsável não se sabe, pois o aviso não possuía autoria e não gerou processo ${ }^{5}$. Nesse caso, de acordo com a lei de liberdade de imprensa promulgada na época responderia por ele o editor ou proprietário do estabelecimento de origem do impresso. Nos dois casos, o mesmo Sr. Meireles ${ }^{6}$. A despeito de sabermos alguns detalhes sobre um episódio que deixou tão poucos rastros, o fato é sem dúvida revelador do contexto pelo qual passavam os anos inicias do novo Império dos trópicos. De um lado, questões políticas mais amplas tomavam conta da cena pública. Redatores ainda sob forte vigília do governo dirigiam suas opiniões sobre variados assuntos. De outro, fatos, como o assassinato de um redator, que aparentemente isolados entre si acabam por demonstrar o quadro de enfrentamentos no qual estavam sujeitos os individuos que tinham na pena e/ou nos prelos suas principais armas de combate. 0 caso narrado, portanto, mais ligado talvez a uma questão local do que diretamente política, não esconde a atmosfera de violência a que estavam sujeitos. Se vasculharmos o Primeiro Reinado não é difícil encontrar episódios em que redatores, livreiros e donos de tipografias eram perseguidos ou calados pelos mais variados motivos ${ }^{7}$. 
Mais ainda, a solução encontrada para o caso de Zefferino acabou

Ilustração é adotada como sinônimo de Iluminismo. Para Francisco Falcon, o lluminismo constituiu o ponto de partida de um controvertido processo de amplo alcance político, econômico e social. 0 autor ressaltou que a razão iluminista instaurou, em definitivo, o reino da crítica e, ao fazê-lo, tinha como alvo "a sociedade como um todo, que deve ser reconstruida". FALCON, Francisco José Calazans. Iluminismo. $4^{\text {a }}$ ed. São Paulo: Ática, 1994. p.39.

9

Utilizaremos análise quantitativa apenas para compreender a intensidade de desenvolvimento da imprensa no diálogo com os diferentes contextos.

\section{0}

Uma amostragem das partes de composição de um impresso pode ser encontrada em: MARTINS, Wilson. A palavra escrita. História do livro, da imprensa e da biblioteca. 2a ed. São Paulo: Ática, 1996. p.288-292.

\section{1}

BLAKE, Augusto Vitorino Alves Sacramento. Dicionário Biográfico Brazileiro. Vol.7. Rio de Janeiro: Imprensa Nacional, 1899. p.413.

\section{2}

A consagração da nobreza nos trópicos analisada a partir de mecanismos simbólicos pode ser vista em: MALERBA, Jurandir. A Corte no Exilio. Civilização e poder às vésperas da independência. São Paulo: Companhia das Letras, 2000. Ver, em especial, o capítulo 2.

\section{3}

DIAS, Maria Odila Silva. A interiorização da metrópole (1808-1853). In: MOTA, Carlos Guilherme (org.). 1822: Dimensões. São Paulo: Perspectivas, 1972. p.160-186.

\section{4}

Estudos clássicos sobre a história da imprensa no Brasil contemplam importantes informações sobre a Gazeta do Rio de Janeiro. Cf. SODRÉ, Nelson Werneck. A História da imprensa no Brasil. Rio de Janeiro: Mauad 1999; VIANNA, Hélio. Contribuição à história da imprensa brasileira. Rio de Janeiro: Imprensa Nacional, 1945. A historiografia recente colocou a Gazeta do Rio de Janeiro como fonte de pesquisa para apreensão de práticas culturais na cidade e como elo entre a Coroa e a sociedade carioca. Para estes, ver: CARDOSO, Teresa Maria R. Fachada L. Gazeta do Rio de Janeiro: subsídios para a história da cidade (1808-1821). Revista do Instituto Histórico e Geográfico Brasileiro, Rio de Janeiro, abr / jun., 1991. SILVA, Maria Beatriz Nizza da. A Gazeta do Rio de Janeiro (1808-1822): cultura e sociedade. Rio de Janeiro: Eduerj, 2007. Juliana Gesuelli chamou a atenção para os impactos na circulação de idéias entre os dois lados do Atlântico e sua maneira de retratar os eventos politicos. MEIRELLES, Juliana Gesuelli. A Gazeta do Rio de Janeiro e o impacto da circulação de idéias no Império luso-brasileiro (1808 -1821). 2006. (Dissertação de Mestrado). São Paulo: Instituto de Filosofia e Ciências Humanas, Universidade Estadual de Campinas, 2006.

15

NEVES, Lúcia Maria Bastos Pereira das. Imprensa Régia. In: VAINFAS, Ronaldo (dir.). Dicionário do Brasil Imperial (1822-1889). Rio de Janeiro: Objetiva, 2002. p.165-166. por revelar outros aspectos implícitos em uma sociedade ainda tipicamente colonial, em que o direito e a prática da opinião difundidas na Europa pela Ilustração $0^{8}$, demoravam para de fato existir. Sob essa ótica e tendo como percurso a trajetória do tipógrafo Vitor de Meireles nossa pesquisa busca elucidar alguns aspectos integrantes das práticas que norteavam o ofício de impressão na cidade do Rio de Janeiro no periodo compreendido entre a chegada da Corte Real (1808) e os anos iniciais do Primeiro Reinado9 9 . De acordo com essa perspectiva, propomos compreender ainda algumas das condições anteriores da vida de Zefferino enquanto percurso representativo para compreendermos os meandros nos quais estavam envolvidas as chamadas "Artes Mecânicas". Complementarmente, vale à pena pensarmos nas condições culturais do contexto de crescimento da atividade tipográfica no periodo.

\section{De almoxarife a administrador: apontamentos para a análise de uma trajetória}

Mais do que trabalho único de reflexão e de escrita, a atividade em torno da imprensa envolve muitos outros aspectos que reunidos dão a forma final a um impresso. Desse modo, a confecção de um livro, de um jornal, ou mesmo de um efêmero folheto, consolida um árduo e paciente trabalho muitas vezes de dificil percepção no conjunto de todo o processo ${ }^{10}$. Ao lermos um impresso não nos damos conta do imenso trabalho e dos minuciosos detalhes requeridos pela prática de tal oficio. Percorrermos a trajetória de um tipógrafo talvez nos ajude a adentrar um pouco mais no universo das Letras, não somente por seu lado nobre, mas também um pouco do suor inevitavelmente impregnado nos prelos.

0 tipógrafo Zefferino Vitor de Meireles nasceu no Reino de Portugal, na cidade de Lisboa, em uma familia de comerciantes. Filho de Manuel Carmo da Silva chegou ao Rio de Janeiro em data desconhecida. Seus registros mostram que teria iniciado seus trabalhos a partir do ano de 1808 na imprensa da cidade, então sede da Corte, ocupando a partir daquela data funções diversas ${ }^{11}$. A despeito de inúmeras lacunas que envolvem essa figura, vale apontar que sua trajetória de vida testemunhou o novo cenário que começava a se desenhar na América portuguesa. Frente à necessidade de construção de uma sociedade culta e ilustrada, digna de conviver com uma monarquia, diversas práticas culturais estavam sendo implementadas. Além da composição da Biblioteca Real da cidade, conforme anunciadas pelos jornais, aulas de línguas (como o inglês e o francês) foram muito valorizadas, posto que acabaram por constituir aspecto peculiar de status para aqueles que almejavam se diferenciar ainda mais dos segmentos mais baixos da população. No plano simbólico, festas e espetáculos serviam para reforçar as linhas de força determinantes do novo contexto que então se apresentava ${ }^{12}$. No bojo de transformações materiais e sociais, nesse processo de interiorização da metrópole ${ }^{13}$, foi implantada a imprensa oficial do governo, a Tipografia da Impressão Régia ${ }^{14}$. Tal medida, no dizer da historiadora Lúcia Neves, contribuiu decisivamente para despertar a vida cultural da colônia criando um canal de comunicação entre o rei e os súditos, além de divulgar as medidas do governo instalado no Rio de Janeiro ${ }^{15}$.

De todo modo, embora não possa ser considerada como iniciadora de uma imprensa opinativa, na qual os impressos representariam essencialmente um espaço de voz e de crítica social, a Tipografia 
Compunham a diretoria administrativa nomeada por D. Rodrigo, os letrados: José da Silva Lisboa (também censor das obras); José Bernardes de Castro (revisor das provas a caminho dos preIos); e o diretor Mariano José Pereira da Fonseca. A este respeito, ver: NEVES, Lúcia Maria Bastos Pereira das. Censura. In: SILVA, Maria Beatriz Nizza da (coord.). Dicionário da História da colonização portuguesa no Brasil. Lisboa: Verbo, 1994. p.157159. A Tipografia da Impressão Régia foi fundada em 13 de maio de 1808. Inicialmente, foi instalada na Rua do Passeio, sendo mais tarde transferida para a Rua dos Barbonos (atual Evaristo da Veiga), onde permaneceu até 1822. Segundo o historiador Carlos Rizzini, após inúmeras mudanças de nome, em 1822, passou a se chamar Tipografia Nacional, título que manteve até 1885. Moraes \& Camargo apontam que a nova tipografia oficial era ligada à Secretaria de Negócios e da Guerra que, na ocasião, administrada por Rodrigo de Souza Coutinho, recebeu essa nova função. MORAES, Rubens Borba de; CAMARGO, Ana Maria de Almeida. Bibliografia da impressão Régia. São Paulo: EDUSP / Livraria Kosmos Editora, 1993. p.XIX.

\section{7}

BLAKE, Augusto Vitorino Alves Sacramento. Dicionário Biográfico Brazileiro. Vol.7. Rio de Janeiro: Imprensa Nacional, 1899. p.413. Zefferino Vitor de Meireles. BN-DMss. Coleção Documentos Biográficos. Rio de Janeiro. Doc. 01 a 16. Cf. SILVA, Antônio de Moraes. Alçador. In:__. Dicionário da Lingua Portuguesa. Lisboa: Tipografia Lacerdina, 1813, vol.1. p.84.

\section{8}

SILVA, Antônio de Moraes. Apontador. In: Dicionário da Língua Portuguesa. Op.Cit. vol 1. p.178.

19

Zefferino Vitor de Meireles. BN-DMss. Coleção Documentos Biográficos. Rio de Janeiro. Doc. 16, 24 de dezembro de 1817.

20

SILVA, Antônio de Moraes. Almoxarife. In: Dicionário da Língua Portuguesa. Op.Cit. vol.1. p.109.

\section{1}

Na concepção de José Murilo de Carvalho, a idéia de elite repousa na noção de grupos específicos, marcados por caracteristicas próprias capazes de os distinguir face às massas e a outros de elite. Cf. CARVALHO, José Murilo de. A construção da ordem: a elite politica imperial. Rio de Janeiro: Campus, 1980. p.20.

\section{2}

Para o perfil dos tipógrafos nos anos de $1820 \mathrm{e}$ 1822, ver: NEVES, Lúcia Maria Bastos Pereira das. Corcundas e constitucionais - a cultura política da independência (1820-1822). Rio de Janeiro: Revan / Faperj, 2003. Prosopografia dos tipógrafos e redatores de jornais disposta no capítulo 1.

\section{3}

Sobre o crescimento dos intelectuais à sombra da Coroa. Ver: NEVES, Lúcia Maria Bastos Pereira das. Intelectuais Brasileiros nos Oitocentos: A constituição de uma 'familia' sob a proteção do poder imperial (1821-1838). In: PRAD0, Maria Emilia (org.). o Estado como vocação. Idéias e práticas políticas no Brasil oitocentista. Rio de Janeiro: ACCES, 1999. p.9-32. da Impressão Régia inaugurou a prática da impressão periódica nos trópicos acabando por ser o palco que deu início à carreira do futuro tipógrafo Zefferino Vitor de Meireles ${ }^{16}$. Segundo Sacramento Blake, o primeiro cargo exercido por Meireles na Imprensa Régia foi o de alçador. Na função, o empregado "era responsável pela guarda dos armazéns" da Tipografia. Moraes Silva ressaltou que alçador era aquele "que levanta algo". Ao que tudo indica, o funcionário iniciava sua carreira realizando algumas das atividades braçais da oficina. De uma forma ou de outra suas atividades demandavam extrema confiança do rei. Em 1813, o funcionário atingia um lugar mais próximo do trabalho na impressão, um degrau representativo em seu crescimento profissional, no cargo de apontador ${ }^{17}$. Na busca de melhor aprofundamento do cotidiano tipográfico vale frisar a multiplicidade de significados subjacentes a esta sua nova atividade. Sendo assim, diversas acepções podem ser avaliadas. 0 dicionarista Moraes Silva destacou a existência de algumas nuances ao redor do termo: 1) aquele que faz as pontas dos instrumentos; 2) aquele que lembra, sugere, aconselha; 3 ) aquele que controla as faltas dos funcionários; 4) aquele que recita o papel do orador para ajudar-Ihe a memória; 5) aquele que marca os erros ortográficos, valorizando, assim, o entendimento ${ }^{18}$. Conforme indicado, embora distintas entre si, todas as tarefas vinculavam-se ao universo do trabalho, da impressão e edição. Para o cargo de apontador, eram exigidas inúmeras habilidades. Os documentos atestam que, enquanto apontador, Zefferino esteve realizando substituições momentâneas, as quais acabaram se consolidando por vários anos ${ }^{19}$. Dentro das noções apresentadas, verifica-se uma gama de atividades: as mecânicas, de um lado, como cuidar dos instrumentos ou marcar os erros de grafia; e as de vigília, de outro, na atenção ao trabalho dos colegas, como pela anotação de suas faltas. Uma terceira função, por sua vez, estaria ligada a uma espécie de supervisão, cuja tarefa seria a de orientar os outros funcionários durante suas atividades.

No mesmo dicionário, o vocábulo apontador aparece ainda relacionado ao termo alvitre. Este último, por sua vez, correspondia à "invenção de levantar dinheiro" ou a de "arrecadador das rendas reais"20. De uma forma ou de outra, se conselheiro ou alvitre, o funcionário esteve inserido em muitos dos ramos da impressão revelando suas imbricações pela intensa justaposição dos trabalhos no interior do campo da impressão. Em meio a tarefas tão distintas e de tamanha especificidade talvez possamos afirmar que o funcionário as desempenhasse coetaneamente. Em outras palavras, cuidando dos instrumentos e controlando as faltas dos colegas, talvez lhe sobrasse tempo para conferir os erros ortográficos dispostos nos impressos, e mesmo, auxiliar na administração das contas da Coroa. Vale notar que no alvorecer do século XIX, na porção tropical do império luso-americano, face a tantas acomodações forjadas no exercício da elite letrada ${ }^{21}$, não era difícil encontrar a sobreposição de funções 22 . Inúmeras conformações passavam a integrar o período inicial da constituição de uma camada média urbana, grupo que, naquele contexto, necessitava da proteção do soberano para manter suas carreiras e que acabou por deixar inúmeros rastros na posteridade 23 . Pelos documentos analisados e pelo que apontou a pesquisa de Lúcia Neves, Vitor de Meireles era funcionário público ligado ao campo da administração e das Letras tornando-se posteriormente 
NEVES, Lúcia Maria Bastos Pereira das. Corcundas e constitucionais - a cultura política da independência (1820-1822). Rio de Janeiro: Revan / Faperj, 2003

\section{5}

SILVA, Maria Beatriz Nizza da. A Gazeta do Rio de Janeiro (1808-1822): cultura e sociedade. Rio de Janeiro: Eduerj, 2007. p.124-125.

\section{6}

Segundo informou Lúcia Neves, compunham a diretoria administrativa nomeada por D. Rodrigo, os letrados: José da Silva Lisboa (também censor das obras); José Bernardes de Castro (revisor das provas a caminho dos prelos); e o diretor Mariano José Pereira da Fonseca. A este respeito, ver: NEVES, Lúcia Maria Bastos Pereira das. Censura. In: SILVA, Maria Beatriz Nizza da (coord.). Dicionário da História da colonização portuguesa no Brasil. Lisboa: Verbo, 1994. p.157-159.

\section{7}

De acordo com Antonio de Morais Silva, punção ou ponção era um instrumento de ferreiros e espingardeiros usados para furar ou marcar peças de cobre, prata ou ouro. No campo da impressão servia para fundir letras. SILVA, Antonio de Morais. Dicionário da Língua Portuguesa. Lisboa: Tipografia Lacerdina, 1813, vol.2. p.86.

\section{8}

Como já ressaltado, José Bernardes de Castro era um dos diretores da régia oficina, acumulando as funções de corretor e revisor das provas a serem impressas.

\section{9}

Tratamos da concepção de letrado como sinônima de erudito. Cf. SILVA, Antônio de Moraes. Corretor. In: __. Dicionário da Língua Portuguesa. Op.Cit. p.557.

30

Tradução livre: o corretor de impressão constitui aquele que lê as provas para marcar a margem por meio de distintos sinais, cobrindo as faltas deixadas pelo impressor na organização dos caracteres. Cf. Correteur. In: DIDEROT, Denis; D'ALEMBERT, Jean Lerond. Enciclopedia ou Diccionaire Raisonné dês Sciences, dês Arts et dês Métiers (1751-1772). Ed.integral. Marsanne: Édition Redom, s.d. CD-Room.

31

Tradução livre: (...) é necessário que conheça muito bem a língua na qual o texto é composto, conforme sugere o bom senso; qualquer que seja a matéria, que se faça com suas luzes; que entenda muito bem da ortografia e pontuação (...). Cf. Correteur. In: DIDEROT, Denis; D'ALEMBERT, Jean Lerond. Ibidem. dono de tipografia 24 . Além das funções de Zefferino, eram de notório realce as funções de escrivão, secretário e guarda-livros. Segundo Maria Beatriz Nizza da Silva, o grupo dos guarda-livros era respeitado por seus conhecimentos em línguas estrangeiras, escrituração mercantil e operações cambiais. Ressaltou a autora que, em 1817, um guarda-livros que se oferecia para "casas de comércio" além de salientar confiança, pois viera de Portugal com passaporte e referências dos trabalhos anteriores, recebeu a formação exigida pela profissão 25 . Sabe-se que na régia oficina as funções de secretário e guarda-livros eram desempenhadas pela mesma pessoa, cujo nome era Francisco Izidoro da Silva, talvez a principal testemunha dos caminhos trilhados bem como da "dedicação" conferida pelo empregado Meireles ${ }^{26}$. Dos trabalhos diretamente ligados à impressão, muitas atividades ainda constituem terreno desconhecido dos historiadores da imprensa ou mesmo dos comunicólogos que dialogam com a história. Um grande exemplo dessas lacunas são aquelas das áreas relacionadas às "oficinas de composição", fundição de letras, "abrição de punções"27, matrizes e gravuras. Ao completar um ano como apontador, por impedimento do diretor José Bernardes de Castro, Zefferino ocupou o lugar de corretor - também identificado na época como revisor 28 .

Embora alguns termos nos pareçam estranhos, os mesmos tornavam-se referência em alguns pontos da Europa onde, a partir da segunda metade do século XVIII, crescia o paradigma das Luzes difundindo noções matizadas pelo olhar dos filósofos enciclopedistas, debruçados na busca de novas definições para o campo das chamadas "Artes Mecânicas". 0 estudo dos termos ligados à composição dos impressos apontou para a influência dos postulados forjados pela Encyclopédie sobre um dos principais dicionaristas lusos da época, um dos autores mais utilizados nos estudos de história: Antonio de Moraes Silva. A questão torna-se mais simples se tomarmos como exemplo uma comparação a partir do conceito de corretor. Para o letrado português Antonio de Moraes Silva, o vocábulo corretor diz respeito "àquele que corrige; que revê ou emenda as provas das obras que se imprimem"29. Para os enciclopedistas franceses, le correcteur de imprimière (corretor de impressão), constitui "celui que lit les épreuves, por marquer à la marge, avec differéns signes ni fités dans l'imprimerie, les fautes que le compositeur a faites dans l'arrangement des caracteres" 30 .

Conforme podemos verificar, nos dois termos, a figura do corretor é aquela que lê e revisa as provas destinadas à impressão cobrindo os possíveis erros dos compositores, buscando, portanto, o perfeito arranjo dos caracteres, na montagem das frases. Na Encyclopédie, encontramos ainda:

(...) il faut qu' il connoisse très bien la langue du moins dans laquelle l' ouvrage est composé; ce que le bom sens sugere dans uma matière, quelle que elle foit; qu' il fache se métier de ses lumières; qu'il entende très bien l' orthographe \& la ponctuation (... $)^{31}$.

Aprofundando a questão, o excerto revela a condição de corretor enquanto uma tarefa dada aos individuos mais qualificados por exigir conhecimentos anteriores que pudessem permitir o envolvimento do "técnico" com a obra, tanto na boa compreensão de seu texto e de sua língua, quanto em sua pontuação e ortografia. Como referido, eram condições apresentadas somente por aqueles que possuiam exímia experiência no campo das Letras. Na tentativa de melhor esclarecer e organizar o trabalho interno na oficina tipográfica, o historiador Nelson 
SCHAPOCHNICK, Nelson. Malditos Tipógrafos. I Seminário Brasileiro sobre Livro e História Editorial. Rio de Janeiro: FCRB, 2004. http:// www.livroehistoriaeditorial.pro.br. Página acessada em dezembro de 2007.

\section{3}

Apud. SCHAPOCHNICK, Nelson. "Malditos Tipógrafos". Op.Cit. p.6. No romance, Ilusões perdidas, Honoré de Balzac apresenta algumas das condições do funcionamento do maquinário tipográfico na França do final do século XVIII. A respeito do trabalho do compositor, destaca a rudeza de seu cotidiano. Devido ao contínuo exercício que faziam para apanhar as letras dos 152 caixotins, receberam o apelido de macacos. Cf. BALZAC, Honoré de. Ilusões Perdidas. 2a ed. São Paulo: Livraria Martins Editora, 1960.

\section{4}

Uma evolução da imprensa, tida no bojo da divisão internacional do trabalho e da organização da classe operária, pode ser encontrada em VITORINO, Artur José Renda. Máquinas e operários - mudança técnica e sindicalismo gráfico (São Paulo e Rio de Janeiro, 1858-1912). São Paulo: Annablume / Fapesp, 2000.

\section{5}

Nireu Cavalcanti destaca que a troca intensa de livros e entre América Portuguesa e sua metrópole era constante desde fins do século XVIII. CAVALCANTI, Nireu. $O$ Rio de Janeiro setecentista: a vida e a construção da cidade da invasão francesa até a chegada da Corte. Rio de Janeiro: Jorge Zahar Editor, 2003. p.146.

\section{6}

Arquivo Nacional do Brasil (doravante ANRJ). Impressão Régia. Caixa 762. Pacote de Diversos. 27 de dezembro de 1768. Doc.1, fl.1.

37

CASTRO, Renato Berbert de. A Tipografia Imperial e Nacional da Bahia (Cachoeira /1823; Salvador /1831). São Paulo: Ática, 1984
Schapochnick ${ }^{32}$ revelou como o livreiro e tipógrafo francês residente na Corte René Ogier entendia em fins do Primeiro Reinado a maneira de funcionar o trabalho do corretor:

os corretores devem estar separados, longe de bulha, e de toda a distração, num lugar bem claro, e enfim numa biblioteca, a ser possivel; deve-se ao menos fornecer-Ihes os livros de que possam necessitar nas suas indagações, e para verificarem as citações 33 .

Ou seja, no complexo processo de composição eram realizados trabalhos como os de montagem das palavras, linhas, páginas e folhas. Situações que impunham condições técnicas e materiais peculiares, e ainda, tal qual acima escrito, um profundo silêncio ${ }^{34}$. É importante chamar a atenção para o fato de que não havia naquele contexto a divisão de tarefas adotada nas fábricas européias. Desse modo, tratava-se de uma técnica artesanal, passada daqueles mais experientes aos mais novos na profissão, fosse por laço familiar, fosse através do trabalho dos aprendizes. Em paralelo, tratando-se de condições tão específicas de trabalho, a construção semântica dos conceitos no âmbito do século XVIII e XIX pode indicar ainda uma prática norteada por uma espécie de missão a ser efetivada pela difusão do conhecimento, entendida como importante passo no caminho para se atingir as almejadas Luzes. Ainda pelo excerto acima verificam-se pormenores capazes de compor um caminho sugestivo no auxílio aos estudos que tratam das relações intrínsecas à cultura impressa nascida na Ilustração francesa e, mais tarde, espraiada no Reino português ${ }^{35}$. Vale destacar que a própria implantação da Tipografia da Impressão Régia na antiga colônia americana atendeu a uma tradição original lusa montada nos moldes da Casa Literária do Arco do Cego, posteriormente chamada de Impressão Régia de Lisboa ${ }^{36}$. Nesse sentido, sua estrutura na metrópole forneceu o modelo para a posterior implantação de sua versão na Corte do Rio de Janeiro, dada a partir de 13 de maio de 1808.

$\mathrm{Na}$ Metrópole, a imprensa oficial era comandada por um diretor geral, que recebia anualmente no exercício da função, a quantia de $600 \$ 000$ (seiscentos mil réis). Segundo encontrado nos documentos, à frente da Junta Administrativa estava um deputado, cujo ordenado era metade do valor pago ao diretor, ou seja, a quantia de $300 \$ 000$ (trezentos mil réis). Na administração, constavam dois mestres-impressores, daqueles "de melhor nota" da Corte. Para cumprir seus trabalhos, recebiam, por sua vez, um, 500\$000 (quinhentos mil réis), e o outro, $250 \$ 000$ (duzentos e cinqüenta mil réis), também anuais. Conforme é possivel verificar já na metrópole os mestres-impressores também desempenhavam funções relativas ao campo da administração.

Ao tratar da criação da Tipografia Nacional da Bahia, Renato Berbert de Castro 37 afirmou que cabia ao mestre cuidar da "orientação, distribuição e supervisão de todos os trabalhos da oficina". Da mesma maneira, era ele quem entregava ao compositor o manuscrito a ser impresso. 0 trecho abaixo fornece uma dimensão de como funcionava uma tipografia, nas primeiras décadas do século XIX:

Este colocado em frente da caixa, tabuleiro dividido em pequenos compartimentos, os caixotins onde os tipos se encontravam distribuidos, dela retirava, um a um os caracteres, e os colocava no componedor, recipiente de forma alongada, até formar uma linha, que era arrumada na galé, lâmina retangular com rebordos em três de seus lados. Após composto um certo número de linhas, eram devidamente atadas para a formação da chapa, com a qual se tira a prova ${ }^{38}$. 
39

MINARD, Philippe. A agitação na força de trabalho. In: DARNTON, R.; ROCHE, D. (orgs.). Revolução Impressa. A Imprensa na França, 1775-1800. São Paulo: Edusp, 1996. p.155-175.

40

0 conceito de imprensa em sua dimensão jornalistica aparece explícito em IPANEMA, Marcelo de; IPANEMA, Cybelle de. Imprensa Fluminense: ensaios e trajetos. Rio de Janeiro: Instituto de Comunicação Ipanema, 1984. p.33.

41

MOREL, Marco. Da Gazeta tradicional aos jornais de opinião. Texto gentilmente cedido pelo autor.

42

SILVA, Antônio de Moraes. "Administrar". In Dicionário da Língua Portuguesa. Lisboa: Tipografia Lacerdina, 1813, vol.1. p.43.

43

MOREL, Marco. Op.Cit.
Segundo Berbert de Castro, por esta chapa o revisor (ou corretor) indicava os enganos da composição, fazendo-a voltar ao compositor para as devidas correções. No momento da impressão, a fôrma era posta sobre o mármore (chapa de ferro ou de pedra) embutida no cofre do prelo. Sobre os caracteres entintados era colocada a folha de papel. Após esse trajeto as folhas de papel eram postas a secar, presas pelas extremidades em cordões estendidos. Depois de secas eram dobradas e somente então seguiam para o encadernador. Embora os detalhes do funcionamento da construção do impresso façam parte de uma relação mecânica, tratar do assunto, na opinião de Philippe Minard, constitui debruçar-se no cruzamento de três tipos de historia: a história da tecnologia; a história das estruturas econômicas (da moldura material); das práticas e padrões de trabalho, caracteristicos de tais habilidades técnicas ${ }^{39}$. Tendo como fio condutor as técnicas de impressão nossa pesquisa centra-se na análise das relações culturais intrínsecas à cultura impressa do período e que trazem em seu bojo uma sociedade fortemente hierarquizada dotadas de regras que regulam a ascensão social. No que concerne ao conceito de imprensa, optamos, desde logo, em considerá-la não apenas em sua perspectiva jornalística - contabilizada no curso de catalogação quantitativa de seus impressos ${ }^{40}$ - , mas, de outro modo, em sua perspectiva ilustrada, tal qual definida pelos enciclopedistas em duas instâncias: a primeira, por seu perfil mecânico, enquanto técnica, aperfeiçoada ao longo do tempo, capaz de aprimorar-se nas produções gráficas. A segunda, por sua dimensão cultural, que abriga seu papel em uma espécie de devir esclarecedor, (conforme encontrado nos anúncios da época) e capaz de propagar as Luzes da razão. Tal definição de imprensa apresenta dupla característica, ao conjugar duas faces: sendo um maquinário de impressão e, ao mesmo tempo, "uma conquista política". Esta última seria, no dizer do historiador Marco Morel, espaço em que se desenvolveria a liberdade de expressão 41 .

Retornando aos trabalhos realizados por Zefferino Vitor de Meireles na Impressão Régia, no ano de 1816 ele foi chamado pelo deputado Silvestre Pinheiro Ferreira para ocupar por dois meses o cargo que o colocaria no ápice de sua carreira profissional. Sendo assim, ao lado de Ângelo Bissum, assumiu o lugar do administrador Lourenço José Alves Pires, anteriormente afastado por motivo de doença. De uma forma ou de outra, Zefferino Meireles chegaria, assim, ao comando da Tipografia do governo posto que administrar para a época era o mesmo que "governar, dirigir"42. Como funcionário público teve especial destaque na medida em que direcionou sua carreira enveredando-se pelo campo das Letras. Desse modo estimamos que a Tipografia da Impressão Régia teria sido o ponto de partida de sua trajetória na América Portuguesa, especialmente pela atividade na redação de seu próprio periódico, em uma nova empreitada que alcançaria cinco anos depois, representando uma demonstração clara de quão restrito era o universo tipográfico no período, seja no que toca ao aspecto humano - com poucos funcionários capacitados para realizar as respectivas tarefas; seja no aspecto ideológico, a fidelidade e identificação pessoal pelos censores e diretores régios, demonstrada por Meireles, que acabou recebendo chamados de grande importância. Conforme destacou Morel, relações de poder como estas revelam dimensões culturais capazes de permitir novos conhecimentos acerca da imprensa periódica da época, bem como dos embates sociais e políticos que esta última ajudou a construir. Nesse sentido a personagem Zefferino Meireles pode ser vista como um ponto importante ganhando aos poucos relevância e credibilidade naquele incipiente mundo letrado ${ }^{43}$. 


\section{4}

A condição de tipógrafo aqui tratada consiste no entendimento dos vários processos de impressão e não meramente na condição de proprietário de tipografia.

45

Zefferino Vitor de Meireles. BN-DMss. Coleção Documentos Biográficos. Rio de Janeiro. s.d. Doc.8.

\section{6}

Pela leitura de muitos dos anúncios do jornal Diário do Rio de Janeiro, outros nomes podem ser identificados como funcionários da tipografia: Luiz Manuel Pereira e Francisco Rodrigues de Almeida, identificados como mestre-deprensas e mestre-livreiro, respectivamente, através da seção "achados e perdidos". Diário do Rio de Janeiro, 05 de junho de 1821.

\section{7}

Zefferino Vitor de Meireles. BN-DMss. Coleção Documentos Biográficos. Rio de Janeiro. Doc. 16, 24 de dezembro de 1817.

\section{8}

Renato Berbert de Castro destacou que, em 1822, o "mestre de imprensa" José Francisco Lopes, para assumir a direção da Tipografia oficial baiana da cidade de Cachoeira, requereu o salário anual de 400 mil réis mais o valor de 100 mil réis de gratificações por trabalhos extras. Apesar de ter a gratificação negada, recebeu dez anos de salário adiantados. Ver: CASTRO, Renato Berbert de. A Tipografia Imperial e Nacional da Bahia (Cachoeira /1823; Salvador /1831). São Paulo: Ática, 1984. p.8-10.

49

Zefferino Vitor de Meireles. BN-DMss. Coleção Documentos Biográficos. Rio de Janeiro, doc.1-16.

50

SILVA, Maria Beatriz Nizza da. Ser nobre na colônia. São Paulo: Editora da UNESP, 2005.

51

Ibidem p.262.

\section{Os caminhos possíveis na busca de reconhecimento e prestígio}

Embora os documentos que tratam da vida de Zefferino Meireles não apresentem muitos dos dados referentes à dinâmica de seu cotidiano e de sua formação enquanto letrado, verifica-se pelas fontes manuscritas que o empregado trazia em sua experiência profissional qualidades especificas essenciais para o desenvolvimento das tarefas de tipógrafo da época 44 , demonstrando "(...) um perfeito conhecimento de Arte Tipográfica, inteira aprovação na Língua latina e (ilegivel) em algumas das línguas vivas"45. Conhecimentos estes, na opinião de Francisco Izidoro da Silva, "preciosos em uma tipografia" e possivelmente adquiridos no Reino de Portugal ao lado de muitos tipógrafos que de lá vieram com a Corte Real 46 especialmente a partir de 1808. Pela análise dos documentos biográficos de Meireles, encontramos confirmações de cargos e elogios do mesmo secretário, em nome dos censores reais ao empregado:

Atento, outrossim, que em todo o tempo que o suplicante serve nesta Régia Oficina (...) tem sempre mostrado um incansável zelo pelo bem do real serviço, preenchendo cabalmente, e com toda a honra, e desinteresse, as incumbências de que tem sido encarregado (...) 47

Tanta dedicação, contudo, realizou-se pelo descompasso entre promoções e aumento de salários. No exercício efetivo de tantos cargos o funcionário esteve sem receber aumentos - os pagamentos "extraordinários" -, o que acabou por gerar posteriormente requerimentos do funcionário ao monarca D. João48. Como resposta, em agosto de 1818, Vitor de Meireles era nomeado oficialmente à condição de vice-administrador da Impressão Régia. Do mesmo modo, era reconhecido como substituto de Lourenço José Alves Reis, na administração, função que ocupou repetidas vezes, como referido, desde 1816. Em paralelo os documento biográficos atestam ainda súplicas do empregado imbuídas do desejo de adquirir a condecoração de oficial "com a mercê do Hábito da Ordem de Cristo". Tal qual afirmou o suplicante a condecoração foi dada pelo monarca a todos os seus súditos como forma de reconhecimento dos trabalhos "extras", em torno dos prelos, na ocasião da chegada da Princesa Dona Leopoldina, em 1816 ${ }^{49}$. Como se sabe, o episódio constituiu um grande acontecimento na vida dos moradores da Corte pela especial simbologia que agregava na relação de admiração bem como de obediência à monarquia. 0 trabalho da imprensa era crucial, portanto, para estabelecer as bases de recepção da princesa e de consolidação dos laços com seus novos súditos fortalecendo a relação destes com os representantes da nobreza. A ascensão profissional seria, por outro lado, a solução para problemas financeiros e de prestígio. Na sociedade da época, "aceitava-se a nobreza como distinção social e detentora de alguns privilégios" 50 . Segundo Maria Beatriz Nizza, no início do século XIX (e, especialmente, após 1818), D. João VI produziu uma "boa safra de titulares". As formas mais visiveis de distribuição, segundo a autora, ligavam-se à concessão do foro de fidalgo da Casa Real, à atribuição de hábitos e, mais raramente, de comendas das três ordens militares (Cristo, Santiago e Avis). Nesse sentido, "a liberalidade do soberano" incidiu também sobre os habitantes do Brasil, concedendo "a uns hábitos e comendas, a outros, postos e oficios; a estes, dignidades e empregos, àqueles, honras e mercês"51. 
52

Para Sirinelli, a história cultural pode ser um marco para a história política revigorada. Esta última, no entendimento do autor, deve "analisar não somente os comportamentos individuais e coletivos e seus efeitos, mas também aquilo que se relaciona com a percepção e as sensibilidades". SIRINELLI, Jean François. De la demeure à l'agora. Por une historie culturelle du politique. In: BERSTEIN, Serge; MILZA, Pierre Milza (dir.). Axes et méthodes de l'historie politique. Paris: PUF, 1998. p.381-398.

53

Zefferino Vitor de Meireles. BN-DMss. Coleção Documentos Biográficos. Rio de Janeiro, doc.16, fl.1, 24 de dezembro 1817.

\section{4}

SILVA, Maria Beatriz Nizza da. A Gazeta do Rio de Janeiro (1808-1822): cultura e sociedade. Rio de Janeiro: Eduerj, 2007. p.12.

\section{5}

Como revisor, Zefferino recebeu "o valor de costume para o cargo", não especificado nas fontes. Como vice-administrador, o funcionário havia solicitado o ordenado de $350 \$ 000$ (trezentos e cinqüenta mil réis). Zefferino Vitor de Meireles. BN-DMss. Coleção Documentos Biográficos. Rio de Janeiro, doc.16, fl.1, 24 de dezembro 1817.

\section{6}

CARVALHO, Alfredo de. Gêneses e Progressos da Imprensa Periódica no Brasil. In: Centenário da imprensa. Revista do Instituto Histórico e Geográfico Brasileiro. Tomo Consagrado à Exposição Comemorativa do Primeiro Centenário da Imprensa periódica no Brasil, Rio de Janeiro, vol.2, Imprensa Nacional, 1908.

\section{7}

Ibidem. p.26.

\section{8}

Seguindo seu raciocínio, trabalhando de segunda a sábado, os aprendizes ganhariam mensalmente $3 \$ 200$ (três mil e duzentos réis), o que daria $38 \$ 400$ (trinta e oito mil e quatrocentos réis) por ano, valor perfeitamente possivel, quando comparados ao salário recebido por Zefferino Meireles.

\section{9}

SCHAPOCHNICK, Nelson. Malditos Tipógrafos. I Seminário Brasileiro sobre Livro e História Editorial. Rio de Janeiro: FCRB, 2004.
Manuscritos, muito representativos na carreira do empregado, deixam transparecer a complexa teia de relações sociais em que esteve inserido. Nesse sentido, enunciam o caminho delicado e sinuoso dos mecanismos de ação dos órgãos da Coroa: um empregado fiel e habilitado que indicado para diversas funções importantes conquistou o devido reconhecimento, mesmo que tempos depois. Contudo, cabe indagar: o que teria levado Zefferino a receber tal reconhecimento? A reunião das qualidades acima apresentadas poderia falar por si só ou o caminho traçado na convivência com políticos, diretores e censores contribuiu para dar destaque ao funcionário? Talvez a junção das duas hipóteses nos leve a alguma resposta acerca de sua trajetória. Respostas dificeis de atingir mas que podem, no entanto, auxiliar os estudos centrados no aprofundamento das relações entre cultura e poder, no microcosmo da Tipografia da Impressão Régia e na própria Corte do Rio de Janeiro ${ }^{52}$. No ano de 1818 , em busca de reunir documentos que atestassem suas qualidades pessoais, o funcionário arrebanhou testemunhas de peso que acabaram sendo de suma importância para o êxito de sua causa. A primeira delas foi por intermédio do tabelião José Pires Garcia, que the confirmou o ordenado anual de $292 \$ 000$ (duzentos e noventa e dois mil réis) ${ }^{53}$. Ao que tudo indica tal quantia assinalada pelas autoridades aparecia em consonância com o costume. A título de comparação - o que muitas vezes serve como instrumento de análise para a compreensão de valores em contextos passados -, vale lembrar que no início da década de 1820 os oficiais responsáveis pela contabilidade da Gazeta do Rio de Janeiro, recebiam a quantia de 126\$968 (cento e vinte e seis mil, seiscentos e noventa e oito réis) ${ }^{54}$ como parte por cada sócio proprietário. Embora esta quantia não seja o total do valor recebido na função, está a menos da metade do que Zefferino passou a receber. Em outras palavras, no lugar de vice-administrador o funcionário Meireles passou a receber mais do que o dobro da cota dos sócios diretores que trabalhavam na contabilidade ${ }^{55}$. Embora os documentos não apontem para todas as respostas às suas solicitações é possível avaliar que o empregado adquiriu prestígio capaz de ser retribuído senão com condecorações com o devido pagamento de seus trabalhos. Por outro lado, verificamos que o salário conquistado pelo empregado era de alto valor quando cotejado com os recebidos pelos funcionários da imprensa oficial no Reino de Portugal ou mesmo com aqueles apresentados por trabalhadores de ramo similar.

Ao estudar o assunto, Alfredo de Carvalho ${ }^{56}$ sinalizou que apesar de restrito o universo humano que compunha o ofício de impressão da régia oficina apresentava outros niveis no interior de suas atividades mecânicas cujos pagamentos variavam conforme as ocupações ${ }^{57}$. Sendo assim, o aprimoramento técnico proporcionado por esse sistema era direcionado principalmente aos aprendizes os quais, uma vez envolvidos no processo, iniciavam recebendo a quantia de $\$ 160$ (cento e sessenta réis) diários. Após um ano na função seriam aumentados para o valor de $\$ 400$ (quatrocentos réis) também diários ${ }^{58}$. De acordo com os valores da época a soma de $\$ 160$ equivalia a dois números avulsos de alguns dos principais jornais da Corte. Ao contrário do que ocorreu com Zefferino, como incentivo para que não faltassem ao trabalho, os aprendizes recebiam gratificações extras.

De acordo com Nelson Schapochnick, os aprendizes deveriam conhecer bem a língua, pois muitas vezes eram incumbidos de produzir a cópia no lugar dos corretores quando os últimos precisavam de auxilio 59 . 
60

A este respeito, ver: CHARTIER, Roger. 0 Homem de Letras. In: VOUVELLE, Michel (dir.). 0 Homem do Iluminismo. Lisboa: Presença, 1997. p.121-122.

61

CÂNDIDO, Antônio. Formação da Literatura Brasileira (momentos decisivos). $5^{\mathrm{a} e d .}$. São Paulo: Editora da Universidade de São Paulo, 1975. p.218-225.

62

Lúcia Neves destacou que Zefferino Meireles compunha o grupo dos indivíduos da elite brasiliense, os quais, em 1822, pensavam em idéias separatistas e cuja idade oscilava entre 20 e 50 anos.

63

Os constantes requerimentos ao monarca, além de contato com tal esfera de poder, revelavam além de tudo um intenso anseio de crescimento por parte do empregado.

\section{4}

Apesar de não encontrarmos documentos que confirmem a saída da Impressão Régia, suas declarações por meio do Diário do Rio de Janeiro, demonstram um desejo do tipógrafo em dedicar-se apenas à redação do seu jornal, emitido a partir de 1821. Diário do Rio de Janeiro, n.4, 05 de julho de 1821.
Apesar dos indícios iniciais como alçador e almoxarife, a grande experiência demonstrada por Meireles no efetivo exercício das inúmeras funções nas quais estava envolvido revelou traços característicos do perfil cultural da impressão no alvorecer do século XIX. Dito de outro modo, o olhar treinado nos detalhes do campo da impressão; o convívio direto com outros letrados e a formação em diversas línguas e a sua ligação com atividades relativas à administração fizeram de sua figura mais do que um simples funcionário da oficina da Impressão Régia. Sob essa ótica entende-se que, por seu percurso profissional, tendo sido ainda redator de seu próprio jornal, a personagem Meireles constitui-se não apenas como intermediário na relação entre sua cultura e sociedade, mas também enquanto um ativo produtor dela. Na condição de latinista e como entendedor de outras línguas, possivelmente realizava ainda traduções, ou mesmo leituras de obras estrangeiras, quando na falta de outros funcionários da real casa tipográfica. Como técnico, dedicado ao condicionamento e organização dos caracteres, conjugava funções, no entanto, bastante complementares. Dessa forma, Vitor de Meireles pode ser entendido enquanto um homem de letras, que, em seu sentido amplo, viveu envolvido em muitas das etapas da escrita e da impressão, no labor diário da lida com um corpo de maquinários e da experiência em todo o universo erudito 60 . Nesse sentido, estando presente por treze anos nos trabalhos em torno da imprensa do governo contribuiu para a produção e a difusão de uma incipiente cultura impressa carioca quando o jogo de forças colocava em cheque o futuro do Império luso-americano. Meireles reforça ainda a noção de que nos primórdios do século XIX, na sede da Corte, reflexão e labor não são pontos separados nos trabalhos que envolvem a rotina da impressão. Ao contrário do que defendiam os enciclopedistas, as práticas braçais e reflexivas coexistiam como partes de um mesmo todo. Na opinião de Antônio Cândido, no contexto que antecedeu a independência, a raridade e a dificuldade da instrução, a escassez de livros, a necessidade de recrutar entre os letrados homens como os pregadores, professores, administradores, deram aqueles homens de saber, "um relevo inesperado" 61.

Enquanto redator do periódico Diário do Rio de Janeiro, a partir de 1821, Zefferino consolidou sua postura ativa desta vez preocupada com a melhoria da cidade e na moldagem de novas formas de viver em consonância com os novos rumos tomados pela cultura européia. Apresentando as habilidades exigidas pelo ofício da época - entre engenheiros, professores, advogados, médicos, redatores e tipógrafos - atuou, unindo o trabalho burocrático de administração às atividades relativas à "República das Letras"62. No tocante ao seu universo de trabalho, Zefferino esteve dedicado a corresponder aos anseios dos principais nomes de peso político do período, ou seja, na defesa pela manutenção da monarquia. Sua vivência entre políticos e letrados fez com que seu cotidiano na Impressão Régia integrasse uma teia de relações de poder63.

\section{Na Impressão Régia: alianças entre saber e poder}

No que respeita a sua formação nas Artes e nas Letras não nos foi possivel encontrar vestígios de uma educação formal, seja em Coimbra, seja nos trópicos. Sua identificação, enquanto membro de um setor dominante letrado tornou-se possível devido aos longos anos que passou dedicado aos trabalhos na Impressão Régia (de 1808 a 1821)64. Este espaço de formação técnica e ideológica ganhou ainda mais relevância como o 
65

ANRJ. "Inventário Post Mortem de Zefferino Vitor de Meireles". ID. 34570. Notação: 8371, maço 433.

\section{6}

Para a noção de superfície social, ver: BOURDIEU, Pierre. A ilusão biográfica. In: FERREIRA, M. M.;

AMADO, J. (orgs). Usos e Abusos da História Oral. Rio de Janeiro: Ed. FGV, 1996. p.183-191.

67

ANRJ. Inventário Post Mortem de Zefferino Vitor de Meireles. ID. 34570. not. 8371, maço 433.

68

Ibidem.

69

NEVES, Lúcia Maria Bastos Pereira das; FERREIRA, Tânia M. Bessone da Cruz. Livreiros no Rio de Janeiro: intermediários culturais entre Brasil e Portugal ao longo do oitocentos. Atas eletrônicas do $3^{\circ}$ Colóquio do PPRLB. Rio de Janeiro: Real Gabinete de Leitura, 2006. http//.www.realgabinete.com.br. Página acessada em novembro de 2007.

\section{0}

Nesse ano, conforme foi destacado, ainda na Imprensa Régia, Zefferino concentrava suas atenções como redator do Diário do Rio de Janeiro, até o mês de abril, quando montou sua Tipografia do Diário situada, inicialmente, na Rua dos Barbonos (atual Evaristo da Veiga).

71

Diário do Rio de Janeiro, n.1, $1^{\circ}$ de junho de 1821.

\section{2}

MOREL, Marco. Pátrias polissêmicas: República das Letras e imprensa na crise do Império português na América. In: KURY, Lorelai (org.). Iluminismo e Império no Brasil: O Patriota (1813-1814). Rio de Janeiro: Editora FIOCRUZ, 2007. p. 15-40

\section{3}

Sobre a influência da geração de 1790 e da figura de Dom Rodrigo de Souza Coutinho, ver: MAXWELL, Kenneth. A geração de 1790. In: Chocolates, piratas e outros malandros: ensaios tropicais. São Paulo: Paz e Terra, 1999. p.157-208.

\section{4}

Ibidem. p.191.

75

Diário do Rio de Janeiro, n.1, $1^{\circ}$ de março de 1822.

\section{6}

Segundo registrou René Rémond, o movimento liberal europeu foi a primeira onda de movimentos que se desencadeou sobre o Antigo Regime, caracterizando o que considerou como sendo a "mola-mestra da arquitetura intelectual" de muitos movimentos posteriores. Nessa perspectiva, o autor defende o liberalismo não apenas como um conjunto de fatos que "explodiram" em determinada época e determinados diretamente por uma classe, mas, ao contrário, como um fenômeno histórico de grande importância que deu ao século XIX "parte de sua cor", contribuindo para "sua grandeza". Para Rémond, o liberalismo consiste numa filosofia global, não estando restrita no aspecto econômico. RÉMOND, René. A Idade do Liberalismo. In: Introdução à história do nosso tempo. 0 Século XIX (1815-1914). São Paulo: Cultrix, 1976. p.25-48. âmbito que promoveu sua socialização entre os demais membros de uma elite letrada (e política), pela ocupação que exerceu e pela carreira desenvolvida no seio da burocracia administrativa e nas áreas relativas à cultura monárquica. Pela análise de seu Invetário Post Mortem ${ }^{65}$ foi possivel verificar que a família do marido e pai, Sr. Meireles, vivia sem grandes luxos tirando seu sustento do próprio trabalho. Ressalte-se que as informações aqui expostas foram possiveis na medida em que encontramos este documento, que apesar de não apresentar detalhes como bairro de moradia e/ou ano de nascimento e chegada na América, forneceu dados importantes os quais nos ajudaram a compor o que Pierre Bourdieu chamou de superficie social66.

Ainda que desconheçamos sua aparência física, pudemos perceber alguns de seus costumes e gostos pela análise do perfil de suas roupas e objetos pessoais 67 . Entre seus objetos tipográficos, característicos de uma rara habilidade, chamamos atenção para dois prelos de pás usados e 108 tipos de long-primer ${ }^{68}$. Um dos escolhidos pela justiça para avaliar seus bens foi o livreiro Manoel Joaquim da Silva Porto69. Estabelecido na cidade desde 1811, Silva Porto montou sua própria tipografia em 1822, um mês antes de seu colega, Meireles. Ao mesmo tempo em que criava seu próprio negócio, a Oficina de Silva Porto e Companhia, feita em sociedade com Felizardo Joaquim Moraes, o livreiro exercia paralelamente o cargo de administrador da Impressão Régia, em 182270, sendo ainda, a partir desse mesmo ano, distribuidor da Gazeta do Rio de Janeiro. Acredita-se que a aproximação entre os dois proveio da atividade que lhes era comum, além da convivência nos anos de 1821 e 1822 no interior da Impressão Régia. Em 1821, a loja de Silva Porto, situada na Rua da Quitanda, foi também chamada de "Loja do Diário", sendo o primeiro estabelecimento a receber assinaturas para o novo jornal de Zefferino ${ }^{71}$. Em contrapartida, Silva Porto assinava a autoria de muitos dos Sonetos Patrióticos publicados pela tipografia de Meireles. Nas palavras de Marco Morel, tais personagens podem ser compreendidos enquanto herdeiros de um "absolutismo ilustrado" e fundadores do "liberalismo político"72. Como homens que articulavam um saber em nome do poder; juntos, compunham o que Kenneth Maxwell73 chamou de geração de 1790, grupo que, segundo o autor, "emprestou racionalidade à análise dos problemas coloniais e projetou um grandioso conceito de império luso-brasileiro"74. As relações pessoais do tipógrafo podem ser vistas do mesmo modo pela avaliação dos colaboradores do jornal. Anunciantes e/ou financiadores que por meio de assinaturas periódicas passavam a fazer parte de seu cotidiano.

Em $1^{\circ}$ de março de 1822, o redator escreveu ao público:

Aproveito a ocasião para agradecer ao iluminado público desta Corte, e com especialidade aos senhores assinantes a constante proteção que tem prestado a este Diário, sem o que eu não poderia ter vencido os muitos obstáculos que desde seu principio tenho encontrado (...). ${ }^{75}$

Se seus nomes não vêm à tona pode-se ter uma avaliação de sua importância se pensarmos na grande duração em que o periódico circulou na cidade e em todos os seus distritos. Mesmo, e em boa parte do tempo, sem a presença de Zefferino, foram 57 anos (quase ininterruptos), acompanhando o crescimento da cidade; contribuindo na promoção da palavra pública e difundindo idéias de monarquia, liberalismo e constitucionalismo ${ }^{76}$. 
77

ENGEL, Magali. Liberalismo. In: VAINFAS, Ronaldo (org.). Dicionário do Brasil imperial. Rio de Janeiro: Objetiva, 2002. p.476-478.

\section{8}

NEVES, Lúcia Maria Bastos Pereira das. Liberalismo politico no Brasil: idéias, representações e práticas (1820-1823). In: GUIMARÃES, Lúcia Maria Paschoal; PRADO, Maria Emília (orgs.). Liberalismo no Brasil imperial: origens, conceitos e prática. Rio de Janeiro: Revan, 2001. p.79.

\section{9}

MEIRELES, Zefferino Vitor de. Plano de trabalho para o estabelecimento de um útil e curioso Diário. Diário do Rio de Janeiro, n.1, 01 de junho de 1821.

\section{0}

NEVES, Lúcia Maria Bastos Pereira das. Leitura e leitores no Brasil (1820-1822): o esboço frustrado de uma esfera pública de poder. Acervo, vol.8, n.01/ 02, p.129, jan-dez de 1995.

\section{1}

É válido ressaltar que o universo político do periodo é encontrado de maneira mais direta durante os anos em que o jornal esteve redigido e editado por Zefferino Meireles. Após o seu falecimento, em novembro de 1822, o novo administrador e a "viúva Meireles", publicaram um jornal mais dedicado a anúncios em geral. Os fatos políticos não recebiam, desse modo, comentários por parte de leitores, apenas vinham retratados por aviso do governo e nas entrelinhas dos anúncios.

\section{2}

JANCSÓ, István; PIMENTA, João Paulo G. Peças de um mosaico (ou apontamentos para o estudo da emergência da identidade nacional brasileira). In: MOTA, Carlos Guilherme (org.). Viagem Incompleta - a experiência brasileira (150012000). Formação: histórias. São Paulo: Senac, 2000. p.140.

83

Diário do Rio de Janeiro, n.6, 06 de junho de 1821.

84

Ibidem.
$\mathrm{Na}$ América, pode-se afirmar que tal ideário foi introduzido pouco a pouco no curso de chegada da Corte Real, e ainda sob a influência de referências intelectuais francesas e inglesas. Com a independência politica em 1822, nosso liberalismo foi se mostrando peculiar atendendo aos anseios de um príncipe e depois de um imperador (Pedro I) resistente em abandonar suas concepções consideradas por muitos enquanto autoritárias e conservadoras. Na opinião de Magali Engel, mesmo na Europa, tal movimento foi dotado de várias facetas sendo ainda reinterpretadas quando em seu uso nos trópicos. Segunda a autora, enquanto alguns intelectuais e políticos baseavam-se nas idéias de liberdade moderna, assentadas em parte nos postulados trazidos à tona por Montesquieu; outros, mais conservadores, defendiam a premissa da existência de desigualdades naturais entre os seres humanos, por sua vez pautadas nas idéias desenvolvidas por Jeremy Benthan e por Thomas Hobbes ${ }^{77}$.

No caso do impressor Meireles, seu liberalismo aparecia inserido no contexto de transformações relativas às questões de representação. Desse modo o liberalismo no mundo luso-americano tomava a força pela "imagem de futuro a alcançar"78. Embora sua opinião esteja na maioria das vezes contida nas "entrelinhas" dos documentos analisados, o constitucionalismo seria uma forma de poder que balizaria sua postura liberal, ou seja, a defesa do soberano mediante o juramento e a obediência à Constituição lusa. Como salientou desde o início, ao receber as matérias para seu jornal exigia que estas atendessem aos limites da razão ${ }^{79}$. Postura esta capaz de deflagrar a sua diretriz política.

A opinião acerca dos rumos da nação portuguesa aparecia em seu periódico e era conduzida de forma a ressaltar a fraternidade dos povos do Império, tendo sido, nos primeiros meses do veículo, sua principal notícia. Assim como outros periódicos situados no mesmo período, o Diário apresentava um público leitor integrante de "uma inédita preocupação coletiva em relação ao político"80. Apesar de reservar um grande espaço destinado a anúncios locais, de uma forma ou de outra, em suas publicações iniciais não deixava escapar questões políticas mais urgentes ${ }^{81}$. Naquele contexto, foram publicadas inúmeras declarações defensoras da união dos habitantes dos "dois hemisférios". Isto se registra, em parte, pelo que lembram os historiadores István Jancsó e João Paulo G. Pimenta, ou seja: "a força coesiva do conjunto luso-americano era indiscutivelmente a Metrópole e o continente Brasil representava para os coloniais pouco mais que uma abstração"82.

Para o redator do Diário do Rio de Janeiro, Zefferino Meireles, o "Brasil" parecia constituir uma parte (das mais importantes) de um Império venturoso, capaz de subsistir mesmo diante da força da natureza. Sua opinião pode ser vista em diversos trechos dispostos no periódico. Na seção TERREMOTOS 83 , Meireles ressaltava a passividade do português a partir de uma comparação com as características físicas, ou seja, a boa localização do território que, a despeito de inúmeros outros reinos como, por exemplo, o do Canadá; o de São Domingos e o da Suiça, "não nos consta ter havido terremoto, pelo menos notável, neste vastíssimo reino do Brasil"84. Observemos que em face de um terremoto político, urgia por parte das elites intelectuais fornecerem ao público uma leitura dos eventos, seja diretamente ou por meio de metáforas.

No início de 1822, preocupado com as repercussões da Revolução Constitucionalista de 1820, o redator publicou um texto em que expunha 
85

Diário do Rio de Janeiro, n.10, 12 de janeiro de 1822.

86

Ibidem.

87

Diário do Rio de Janeiro, n.10, 12 de janeiro de 1822. A respeito do vocábulo reino, tomamos emprestada a noção de Guerra: constituia-se como "uma unidade política completa, englobando múltiplas comunidades locais, que uma vez localizadas nos trópicos, uniam-se por um território composto pelas mesmas instituições e por um mesmo governo". GUERRA, FrançoisXavier. A nação na América espanhola: questão das origens. Revista Maracanan. Ano 1, n.1, 1999 / 2000. p.9-30.

88

Diário do Rio de Janeiro, n.5, 06 de agosto de 1821. (grifo meu). mais claramente sua visão acerca dos últimos acontecimentos cujo título era: Memória Liberal, Política e Constitucional, na qual se provam os motivos porque se deve estabelecer a Corte Lusitana no Centro dos Domínios da América Meridional ${ }^{85}$. No texto, o editor Meireles deixava claro a sua insatisfação quanto ao desejo das Cortes portuguesas de retorno do monarca d. João VI, para Portugal:

\begin{abstract}
Não he sem a maior mágoa do nosso coração, e de muito honrados portugueses que se ouvem, e lêem opiniões contrárias a Boa Ordem. 0 espírito Público acha-se na maior espectação; todos desejam o bem; porém nem todos têm coragem de reclamar os seus direitos com prudência e moderação [...] Esta obra é oferecida à Generosa nação Lusitana e dedicada a SAR., o príncipe regente Constitucional. Nesta obra se prova evidentemente que a Corte do Império Lusitano deve ser no Brasil (...) 88 .
\end{abstract}

Mais à frente, atingia seu objetivo:

(...) procuram manter-se os laços da mais estreita união entre os lusitanos de ambos os Hemisférios; mostra-se que os habitantes do Brasil são tão dignos e beneméritos com os habitantes de Portugal (...) 87 .

Os laços que muitos dos colaboradores do Diário buscavam manter firmes, apareciam ainda nos sonetos da época. Nos escritos de leitorescolaboradores, estampados no Diário do Rio de Janeiro, virtudes lusas compunham os sentimentos entre portugueses dos dois hemisférios. Durante os meses de junho a agosto de 1821, apareciam, especialmente, sob a forma de Odes e Sonetos. Apresentadas em letras maiores do que o costume, em destaque frente às outras notícias (no que respeita tamanho e preenchimento), estas manifestações constituíram-se como um forte mecanismo de moldagem das leituras da Corte. A dimensão da idéia de nação aparecia especialmente revestida, antes de tudo, pelo significado de ser português. Manifestações de amor à nação e à pátria lusas, apareciam constantemente, colaborando para a idéia de um cenário de fraternidade entre os indivíduos dos dois lados do Atlântico.

$\mathrm{Na}$ concepção de alguns dos leitores do Diário, era importante ressaltar antigos valores de seu imaginário enquanto dispositivos possiveis de luta para selar o bom entendimento entre os habitantes do Império lusoamericano. Ressaltando os laços de união que atavam os portugueses, em agosto de 1821, o Diário anunciava a seguinte dedicatória:

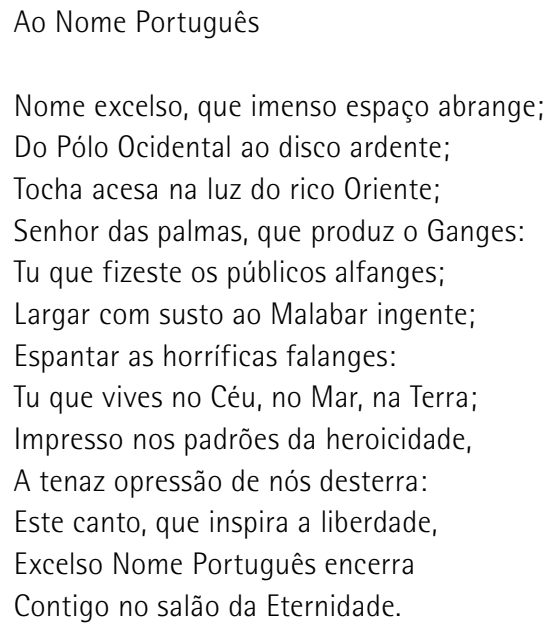

Por F.F.Z. 88 
89

Para o tratamento da esfera pública na América ibérica, nos valemos das assertivas do professor François-Xavier Guerra. De acordo com Guerra, a esfera pública é fruto da participação de variados estratos sociais, resultado de experiências culturais comuns, não podendo ser demarcada apenas pela atuação de uma única classe. GUERRA, François-Xavier. Modernidad y Independencias: ensayos sobre las revoluciones hispanicas. México: Fondo de Cultura Económica, 1992. p. 302

90

Diário do Rio de Janeiro, n.5, 05 de junho de 1821.

91

Diário do Rio de Janeiro, n.1 a 30, 01 a 30 de junho de 1821.

92

Diário do Rio de Janeiro, n.6, 6 de junho de 1821.
$\mathrm{Na}$ expectativa de atingir seus iguais, habitantes de um mesmo Império (português), o texto destaca a grandiosidade de suas dimensões geográficas; a elevada posição do Reino no coração dos súditos; o caráter heróico e eterno de sua história. Características moldadas em um passado distante mas que perpassavam ao longo de sua história recebendo novas dimensões. A idéia de glória como um valor ao Reino de Portugal está presente em inúmeros documentos ao longo da expansão lusa, usadas intensamente desde o final do século XVIII no discurso de intelectuais e políticos.

Pensando na força de seu periódico enquanto espaço de construção de modos de viver e pensar, Zefferino Vitor de Meireles fazia crescer seu principal empreendimento ${ }^{89}$. Em suas declarações, dispostas nos primeiros números do jornal, o redator parecia comparar aquela publicação a um grande compromisso, uma "árdua empresa"90, um sacrifício necessário para se atingir o progresso. Nesse sentido, com redação e edição diárias, seu ofício seria uma "penosa tarefa"91, a ser observada abaixo:

logo que, em razão do bom acolhimento que felizmente vai tendo esta árdua empresa, possa prudentemente dedicar-se unicamente a este ramo de serviço Público esmerar-se em levar, quanto Ihe for possivel, ao maior grau de perfeição tão útil estabelecimento, cujas grandes vantagens, talvez em breve tempo, a experiência comprovará de uma maneira infragável [... ${ }^{92}$

Por suas palavras verifica-se que o periódico apresentou uma feição bem mais rica daquela difundida pela historiografia. Nota-se, assim, uma postura norteada pelo objetivo de instruir o público leitor acerca das inovações científicas do mundo europeu contribuindo para fazer da cidade sede do Império português um local "digno" de abrigar costumes mais modernos tão em voga na Europa. A partir desses escritos e declarações oficiais nota-se que o Diário deixava de ser uma simples vitrine de notícias para se apresentar enquanto um veículo capaz de conter os mais distintos valores e práticas de sua sociedade. A amplitude de sua área de atuação demonstra uma identificação com a evolução da cidade expressa na tabela abaixo:

TABELA 1

\begin{tabular}{|l|l|l|l|c|}
\hline \multicolumn{1}{|c|}{$\begin{array}{c}\text { Área } \\
\text { distrital }\end{array}$} & Estabelecimento & \multicolumn{1}{|c|}{ Localidade } & \multicolumn{1}{c|}{$\begin{array}{c}\text { Responsável } \\
\text { subscrições }\end{array}$} \\
\hline $1^{\circ}$ distrito & Botica & $\begin{array}{l}\text { Rua da } \\
\text { Quitanda, n 41. }\end{array}$ & João Ferreira de Sampaio & 398 \\
\hline $2^{\circ}$ distrito & Botica & $\begin{array}{l}\text { Rua da } \\
\text { Quitanda, } n^{\circ} \text { 109. }\end{array}$ & $\begin{array}{l}\text { Fortunato Justino Rangel e } \\
\text { Maia }\end{array}$ & 295 \\
\hline $3^{\circ}$ distrito & Botica & $\begin{array}{l}\text { Rua dos } \\
\text { Ferradores. }\end{array}$ & $\begin{array}{l}\text { Antonio Lucas da Cunha } \\
\text { Castello Branco }\end{array}$ & 152 \\
\hline $4^{\circ}$ distrito & Botica & $\begin{array}{l}\text { Rua dos } \\
\text { Barbonos }\end{array}$ & José Caetano de Barros & 122 \\
\hline $5^{\circ}$ distrito & Botica & $\begin{array}{l}\text { Largo das } \\
\text { Laranjeiras }\end{array}$ & $\begin{array}{l}\text { Sebastião Vieira do } \\
\text { Nascimento }\end{array}$ \\
\hline $6^{\circ}$ distrito & Botica & Cidade Nova & João Maria da Luz & 40 \\
\hline $7^{\circ}$ distrito & Botica & Mataporcos & Salvador da Silva Fidalgo & 4 \\
\hline
\end{tabular}

FONTE: Diário do Rio de Janeiro, n 6, 07 de julho de 1821.

Conforme mostrado na Tabela 1, havia uma estreita aliança entre o editor Meireles e os comerciantes, especialmente os donos de Boticas. No período contemplado pela análise foram constantes os anúncios de boticas como locais de assinatura de novas obras. Sendo assim, entendemos que 
93

Como afirmou Roger Chartier, a leitura é uma prática cultural e, antes de tudo, "uma ação criadora, inventiva e produtora", não podendo ser anulada no texto lido. Cf. CHARTIER, Roger. Práticas de leitura. São Paulo: Editora Estação Liberdade, 1996. p.78. a quantia de cerca de mil exemplares como tiragem do Diário do Rio de Janeiro (tidas em julho de 1821), em face de uma população de maioria analfabeta, pode ser considerada um sucesso em termos empresarias por estampar ainda atitudes convergentes de parte dessa elite residente na Corte na perspectiva de dirigir de maneira correta a veiculação dos eventos.

Para tanto, a concepção dos indivíduos acerca de sua identificação com a pátria e com sua nação constava nas prioridades de suas ações, aparecendo de forma constante no periódico notadamente em 1822. Nas páginas do Diário do Rio de Janeiro a leitura se fazia a partir da articulação de um grupo de referenciais culturais (e simbólicos); manifestados não apenas pelo ato de ler, mas também pelo ato de fidelidade ao comprometer-se com ela fazendo-a repercutir dentro e fora de seu espaço de origem ${ }^{93}$. Diante de tão distintas realizações no campo das Letras entendemos que a figura de Zefferino Vitor de Meireles conjugou múltiplas formas que acabaram por alimentar nossa perspectiva de compreendê-lo como um significativo agente cultural e político do início do oitocentos, e cuja trajetória confunde-se com a própria história de consolidação da atividade impressora na cidade em que a expansão de um espaço público de informação e de crítica forjou-se como meta na construção e divulgação do saber informativo e utilitário, instrumento da razão e construtor de um almejado progresso futuro. 